\title{
A 100 años de la Bauhaus, su influencia en la educación actual
}

M.E. Mónica del Carmen Aguilar Tobin

Universidad de Sonora

monica.aguilar@unison.mx

\section{Resumen}

En este trabajo realiza una revisión documental acerca de la metodología educativa de la escuela la Bauhaus y su influencia en la didáctica del diseño. Se contemplan sus diversas etapas de desarrollo desde su fundación y las influencias que hubo en ella, hasta su extinción en Alemania y su migración a América, con el fin de conocer cuál es su proyección dentro de los planes de estudio de las escuelas actuales, los elementos más destacados de esta pedagogía y cómo vinieron a cambiar la manera de enseñar el diseño.

\begin{abstract}
This paper makes a documentary review about the educational methodology of the Bauhaus school and its influence on design didactics. From its foundation and its influences, until its extinction in Germany and its migration to America, in order to know what its projection is within the curricula of the current schools, most prominent elements of this pedagogy and how they change the way of teaching design.
\end{abstract}

\section{Introducción}

Este año se conmemoran 100 años de la fundación de la Bauhaus, una de las escuelas de arte y diseño más influyentes del siglo XX. Fundada por el arquitecto Walter Gropius en el período de entreguerras con el interés de aportar a la construcción de una nueva sociedad, su objetivo fue preparar a arquitectos, escultores y pintores de toda categoría para convertirlos en artistas, artesanos o creadores y fundar una comunidad de trabajo que estuviera formada por maestros y aprendices que fueran capaces de crear obras completas: desde la construcción hasta los acabados, decoración y equipo, respondiendo en conjunto a la misma intención. Nuestro propósito en este trabajo es conocer la influencia de esta escuela en la manera de enseñar el diseño.

\section{EI nacimiento de la Bahaus}

La Bauhaus abrió sus puertas el primero de abril de 1919, un folleto anunciaba su programa de estudios que fusionaba los programas de la Academia de Bellas Artes de Weimar y de la antigua Escuela de Artes y Oficios del Gran Ducado" . El objetivo principal contenía un concepto radical: el replanteamiento del mundo material para reflejar la unidad de todas las artes. Gropius redacta el manifiesto de la Bauhaus en donde describe una escuela que combinaba arquitectura, escultura y pintura en un solo producto creativo, hace un llamado a arquitectos, pintores y escultores a volver al oficio artesanal: 


\section{MANIFIESTO}

Weimar, abril de 1919

Arquitectos, pintores, escultores: ¡debemos volver a la artesanía!

¡Construyamos pues un nuevo gremio de artesanos sin la distinción de clases que levanta un muro de arrogancia entre artesanos y artistas! Permitámonos todos juntos deseear, concebir y crear el nuevo edificio del futuro, que combinará todo en una única forma: arquitectura, escultura y pintura, y que un día se alzará hacia el cielo de la mano de un millón de artesanos como símbolo cristalino de una nueva fe." (Gropius, 1919) ${ }^{1}$

\section{Los orígenes}

En 1918, Bruno Taut funda el Consejo de Trabajo para el Arte, (Arbeitsrat für Kunst) con el objetivo de crear una arquitectura para una nueva sociedad que emergía de la destrucción causada por la primera guerra mundial. (Kenneth, 1981 p:83). Taut tenía la convicción que la unión de todas las disciplinas en un nuevo arte aportaría una nueva unidad cultural, ideales que Gropius retoma y en los que basa la filosofía de esta nueva escuela. El programa que Gropius creó, era un programa de estudios artesanales para la enseñanza del diseño basado en laboratorios y talleres, tanto para diseñadores como para artesanos cuya intención era la creación de objetos útiles y hermosos, así como compatibles con "la nueva sociedad" que el mundo estaba demandando en ese momento.

Otra corriente en la que la escuela se basa es en el movimiento inglés Arts and Crafts, el cual, en respuesta a la revolución industrial quería rescatar la actividad artesanal, agregando al objeto utilitario el valor estético. La Bauhaus busca la fusión entre el producto artístico y la nueva realidad social, atiende así a esa necesidad de resaltar la esencia de las cosas y dejar de lado los objetos que otorgan valor únicamente a su sentido estético.

\section{El plan de estudios}

Gropius, para lograr sus propósitos, armó un equipo conformado por artistas de Vanguardia, como Vassily Kandinsky, pintor y teórico del arte, originario de Rusia; Paul Klee, pintor alemán; George Muche, Johanes Itten y Oskar Schlemmer artistas gráficos y teóricos del arte, entre otros, que le darían renombre a la escuela. El plan de estudios rompía con todas las propuestas de la academia clásica al proponer un regreso a los talleres artesanales, con el objetivo de unir a las artes a través de los oficios. En una primera etapa, el programa de la escuela abarca todas las artes. De acuerdo a Boris Friedewald en él

"se cursaba un ciclo básico de 6 meses -establecido por Johannes Itten-, el cual funcionaba como preparación para los siguientes estudios donde se experimentaba con formas abstractas y materiales naturales, se basaba en la experiencia directa, así como el desarrollo de la conciencia perceptiva, la capacidad intelectual y la experiencia emocional (como se cita en Muñoz, 2010, p: 71).

La intención de este curso preliminar era eliminar las ideas preconcebidas con las que llegan los estudiantes y con ello sentar las bases para desarrollar su potencial creativo. En su trayectoria escolar cada estudiante estaba acompañado por dos maestros: un maestro artesano y un maestro de teoría.

En sus orígenes, la Bauhaus comenzó con 4 talleres: metales, impresión gráfica, encuadernación y tejido. En el segundo año se incorporaron otros como muralismo, escultura en piedra y madera, cerámica y vitrales, para después incorporar carpin- 
tería y arte dramático. En 1923, se aplica un enfoque hacia el diseño aplicado, a tal grado que Gropius cambia el lema de la escuela de "Por la unidad del arte y la artesanía" a "Arte y tecnología, una unidad nueva", esto con el fin de evidenciar la presencia de la industrialización, para posicionar a la Bahuahus como punta de lanza en cuestiones de diseño arquitectónico, industrial y gráfico (Muñoz, 2010). Wingler (1975), documenta los tres objetivos de la escuela: el primero consiste en reunificar todas las disciplinas artesanales en una nueva arquitectura como partes inseparables de la misma; el segundo presenta la búsqueda de la "obra de arte unitaria" sin una clara diferenciación entre lo estructural-monumental y lo decorativo; el tercero presenta la conformación de la escuela un espacio donde convivirían maestros y aprendices creando de forma colectiva.

Wick (1986), menciona la estructura organizativa en tres cursos: uno para aprendices, el segundo para oficiales y un tercero para maestros jóvenes. En el documento oficial no se establecía como serían en la práctica los cursos, solamente se acota que la enseñanza artesanal es un componente esencial, no es sino hasta 1922 que se explican las características de cada una de las etapas formativas: Primer curso: "Instrucción de preparación", duraría seis meses y consistiría en un entrenamiento en diseño básico y experimentación con diferentes materiales. Segundo curso: "Instrucción técnica" donde se avanza en cuestiones de diseño y los talleres se vuelven más importantes. Esta etapa tiene una duración de tres años y al concluirla el estudiante recibía certificado de estudios por la Bauhaus. Tercer curso: "Instrucción estructural para alumnos destacados", estaba dirigido a aquellos alumnos que habían sobresalido en sus estudios preliminares, y consistía en la práctica de trabajo en edificios, a la par que entrenaban en el departamento de investigaciones de la escuela. Al finalizar este curso, el alumno obtenía el título de maestro constructor.

Hacia 1925, una buena parte del cuerpo docente de la escuela, estaba compuesta por exalumnos hecho que dio pie a un desarrollo pedagógico diferente, ya que los docentes cumplían con el perfil de maestros de la forma y maestros artesanos simultáneamente. Es hasta 1927 que se constituye el departamento de arquitectura de la Bauhaus, esto no había sido posible, por falta de apoyo financiero. La apertura del departamento llega a ser un parteaguas en la escuela, pues se convierte en el centro alrededor del cual giran el resto de las disciplinas artesanales y artísticas que se convierten en auxiliares. El director fue Hannes Meyer (1889-1954) quien le da fuerza al plan de estudios de la escuela con el desarrollo de una enseñanza técnica, pero a la vez muy funcional, profundizando en los preceptos científicos que la hicieron sólida. Al convertirse el departamento de arquitectura en un elemento tan fuerte, el resto de los talleres se convirtieron en materias auxiliares de la construcción, cuestión que viene a contradecir la anterior ideología del artista creador. (Wick, 1986).

Paradójicamente, al mismo tiempo, los talleres adquieren relevancia tanto por lo novedoso de sus diseños como por el hecho de desarrollar un arte práctico, al alcance de la sociedad, esta misma búsqueda, conlleva que estos talleres queden al servicio de la arquitectura.

Paralelamente a los cambios estructurales que se fueron realizando a lo largo de los años en los planes de estudio de la escuela, la formalización de estos estudios se va realizando de manera progresiva. Es de resaltar que la importancia que se le dio al desarrollo individual del artista y a la artesanía, evolucionó a un modelo 
diametralmente opuesto en donde se frena este libre albedrío del artista y se le da más importancia a la producción en serie de los objetos diseñados (Hernando, 2018).

\section{El diseño de la Bauhaus}

En el año de 1923, cuatro años después de su fundación, la escuela presentó al público por primera vez el trabajo que se hacía en la institución. Se expone el diseño y construcción de una casa con todo su mobiliario, se trataba del prototipo de la casa moderna del futuro. La exposición "das Haus am Horn" fue un éxito. Había nacido el diseño industrial (Alcaraz, 2019). Entre los productos destacados de la Bauhaus, que se convirtieron en iconos representativos del movimiento, destacan los productos de acero de Marianne Brandt, los textiles del taller de Gunta Stölzl, muebles de Alma Buscher, y en diseños individuales, objetos como la lámpara Bauhaus de Willhem Wagenfeld, la silla Vassily de Marcel Beuer y la famosa cuna de Peter Keler, entre algunos otros. Las reproducciones de estos diseños continúan aún en el mercado.

En cuanto a la arquitectura, el movimiento fue un parte aguas: las características que distinguían a los diseños más representativos del movimiento eran elementos nunca antes vistos en cuanto a composición se refiere: estructuras cúbicas, asimétricas, techos planos y ventanales monumentales, techos planos y la utilización del concreto armado y el vidrio como materiales principales. Uno de los principios de la escuela era que los materiales debieran reflejar la verdadera naturaleza tanto de los objetos como de los edificios, por lo que no se ocultaban los materiales por motivos estéticos, el arquitecto no escondía los elementos de construcción, con ellos se mostraban las vigas o el acero en un edificio. Algunas de las construcciones más representativas de la ideología de Gropius son el edificio sede de la misma escuela, en Dessau y la "Haus am Horn", ambos diseñados por él mismo (Alcaraz, 2019).

"La forma sigue a la función", uno de los principios fundamentales de la escuela, donde se establece que la utilidad del diseño siempre debe prevalecer sobre la estética, premisa que hace desechar los elementos innecesarios en una composición. Dando como resultado el estilo característico de la escuela, que permeó en todas las artes, en las artes gráficas, por ejemplo, Herbert Bayer, diseñó una tipografía minimalista, clara, geométrica y planteada únicamente en cajas bajas, explicando la propia escuela que atendía al uso lingüístico, es decir, para que hubiera una congruencia entre el modo de hablar y escribir, argumentando que no hablamos con sonidos mayúsculos, por lo tanto, tampoco se escribiría de esa manera (Friedewald, 2009).

El minimalismo es otra característica representativa de la escuela, en congruencia con lo arriba mencionado, la sencillez en los materiales y los elementos, así como la funcionalidad, se reflejaban en un estilo minimalista. Los artistas pertenecientes al movimiento, estaban influenciados por el movimiento moderno de "De Stijl", caracterizado por formas geométricas y lineales y la utilización de colores primarios.

\section{Cambios}

Concluye la primera etapa de la escuela, ya que las creaciones radicales de la misma comenzaron a contrastar con el pensamiento de la conservadora ciudad de Weimar, cuyos habitantes comenzaron a hacer presión, hasta que el gobierno local rescinde el contrato de Gropius en 1925. Pero era ya tal la fama que la ciudad de Dessau que, Sajonia Anhalt, ofreció su territorio para alojar a la escuela; con esto viene el cambio de sede y comienza la segunda etapa de le escuela ahora bajo el 
lema "Técnica y arte en una nueva unidad".

Sin embargo, el grupo sigue llamando la atención por sus ideas, y recibiendo hostilidades. Walter Gropius deja la dirección de la escuela en febrero de 1928 y el cargo lo ocupa el Arquitecto Hannes Mayer y con él comienza una nueva etapa que pretende poner el arte al alcance del pueblo más que de la burguesía.

Estas ideas comunistas del nuevo director se convirtieron en el motivo de su despido a mediados de 1930, ocupando ahora el cargo el arquitecto Ludwig Mies van der Rohe, quien intentó excluir a la escuela de todo movimiento político y enfocarse en el academicismo, sin embargo el partido Nacionalsocialista presionó para que el ayuntamiento de Dessau cerrara definitivamente la escuela.

Van der Rohe después de esto muda la escuela a Berlin, pero con el nazismo en el poder la existencia de la Bauhaus termina de manera definitiva en 1933. Para entonces muchos de los profesores y exprofesores poseían ya fama internacional, lo que dio lugar a que algunos de ellos tuvieran buenas ofertas de trabajo en Estados Unidos. Esto incluye a Gropius, Mies van der Rohe, Anni Albers, Feininger, Moholy Nagy, Bayer y Beuer, algunos de ellos expresaron que sus diseños fueron su pasaporte. Otros, por el contrario, no tuvieron la misma suerte, y se estima que entre veinte y treinta de ellos murieron en los campos de concentración o algunas otras consecuencias de la segunda guerra mundial (Kennedy, 2006).

\section{La influencia}

La influencia de la pedagogía de esta escuela no comienza con su cierre, se puede apreciar en la República de Weimar, en la formación de artistas profesionales y en la educación estética de las escuelas. (Wick, 1986). Al emigrar de Weimar, la Bauhaus continuó su tradición, debido a la influencia de la escuela en los profesores de la localidad. Antje Middeldorf (Citado en Wick, 1986), identifica en la enseñanza profesional de esa época en Alemania, ciertos principios de la institución como el respeto por la obra, la economía y la utilidad.

Con el exilio de los docentes de la escuela hacia Estados Unidos, este país se convierte en el principal receptor de la actividad profesional por parte de este grupo, considerando que sus actividades las realizaban la mayoría en distintas Universidades, podemos explicarnos la expansión de estos métodos docentes. Hernando menciona: "Se trasladan así a un contexto social en el que no tuvieron que preocuparse por la persecución política o las necesidades económicas, pudiendo dirigir sus conocimientos arquitectónicos a través de universidades o cursos especializados de arquitectura interesados por el conocimiento del oficio."

Walter Gropius se convierte en el director del departamento de arquitectura de la Universidad de Harvard en 1937, lugar donde aplica los fundamentos pedagógicos que él mismo estableció en la Bauhaus. Además de él, Mies van der Rohe, en 1938 es contratado como profesor en el Armour Institute de Chicago. Por su parte, ahí mismo en Chicago, Moholy-Nagy había fundado un año antes la New Bauhaus, que después llevaría el nombre de Institute of Design. La Universidad de Yale, contrata a Joserf Albers como director del departamento de diseño, puesto que desempeñó hasta 1958. Según Wittenberg, "Mies van der Rohe, con su estilo arquitectónico de lineas precisas, elegantes y sutiles representará el llamado estilo Bauhaus en América y marcará las bases de la nueva arquitectura en ese país" (Citado en Hernando, 2018). De esta manera, las prácticas pedagógicas, los ideales y pensamientos sobre el diseño, se van incrustando desde las ins- 
tituciones más influyentes en la estructura educativa del diseño en el continente americano (Hernando, 2018).

\section{Conclusiones}

Podemos afirmar que el modelo actual de enseñanza del arte, está basado en la metodología de enseñanza de la Bauhaus, muchos de sus principios, ideas y estrategias las podemos encontrar hoy en día en las instituciones de enseñanza, aunque cabe decirlo, no siempre reunidas en su totalidad. De acuerdo a Bravo (2015, p:
81), la formación del ser integral, primero como humano y luego como artista, por encima del dominio de la técnica, es aplicado en la formación de diseñadores y artistas, desde nivel técnico hasta el nivel profesional, más allá de un dominio de la técnica y la práctica, lo cual es básico para el desempeño profesional, la creatividad y la integralidad será lo que permita al individuo ofrecer soluciones innovadoras frente a las exigencias de su comunidad y de sobresalir en un mercado competitivo.

\section{Referencias}

Alcaraz, Y. (Junio 2019). El centenario de la Bauhaus. Proceso, 23, 58-91.

Bravo, R. "Vigencia de la Bauhaus en la formación académica de los diseñadores gráficos". Calle14: revista de investigación en el campo del arte, 10 (17), 2015. p. 81.

Frampton, K. (1981). Historia Crítica de la Arquitectura Moderna. Barcelona, G. Gili.

Friedewald, B. (2009). Bauhaus, London, Prestel.

Hernando M., (2018) Pedagogía de la Bauhaus, Tesis de grado) Universidad de Salamanca, España.

Kennedy, A. (2006). Bauhaus, London, Flametree publishing.

Wick, R. (1993) La pedagogía de la Bauhaus, Madrid, Alianza Forma.

Wingler, H. (1975). La Bauhaus: Weimar, Dessau, Berlin: 1919-1933. Barcelona, G.Gili. 